\title{
Distal cap to facilitate removal of blood clots during endoscopic hemostasis for upper gastrointestinal bleeding
}

Endoscopic treatment is available for variceal and nonvariceal upper gastrointestinal (UGI) bleeding [1,2]. Blood clots in the stomach hamper endoscopic treatment by obscuring the bleeding source. Aspiration of clots, however, results in obstruction of the working channel, while grasping clots with a basket or snare leads to cutting up of the clots [3]. We describe the usefulness of an attachable distal cap to remove blood clots from the stomach during endoscopic treatment of UGI bleeding.

Two patients in the intensive care unit had active UGI bleeding with hemodynamic instability requiring transfusion. Urgent UGI endoscopy revealed blood clots filling the stomach, obscuring the bleeding source. Attempts to remove the clots using aspiration and a polypectomy snare were unsuccessful. To improve the aspiration force and contact surface, we attached a distal cap intended for esophageal endoscopic mucosal resection (Disposable Distal Attachment D-206-04; Olympus Medical Systems Corp., Tokyo, Japan). This cap has an oblique shape (18 $\mathrm{mm}$ diameter) with a distal rim. As can been seen from $\bullet$ Fig. 1 and 2, the cap allows firm aspiration of large blood clots, which can be easily removed from the stomach with retraction of the endoscope.

After removal of the gastric clot, a bleeding fundic ulcer was seen in the first patient and a bleeding fundic varix in the second; both were controlled by conventional endoscopic hemostatic treatment. Disposable distal attachment caps are available to facilitate mucosal resection and submucosal dissection procedures. We present two cases of UGI bleeding in which the use of a rimmed oblique cap was helpful to remove blood clots from the stomach during endoscopic hemostasis. Clots were aspirated into the cap, and the wide oblique opening with rim proved ideal to keep the clot inside the cap while retracting the endoscope. By repeating this procedure, the stomach was rapidly cleared of clots, the bleeding source was visualized, and endoscopic hemostasis performed.

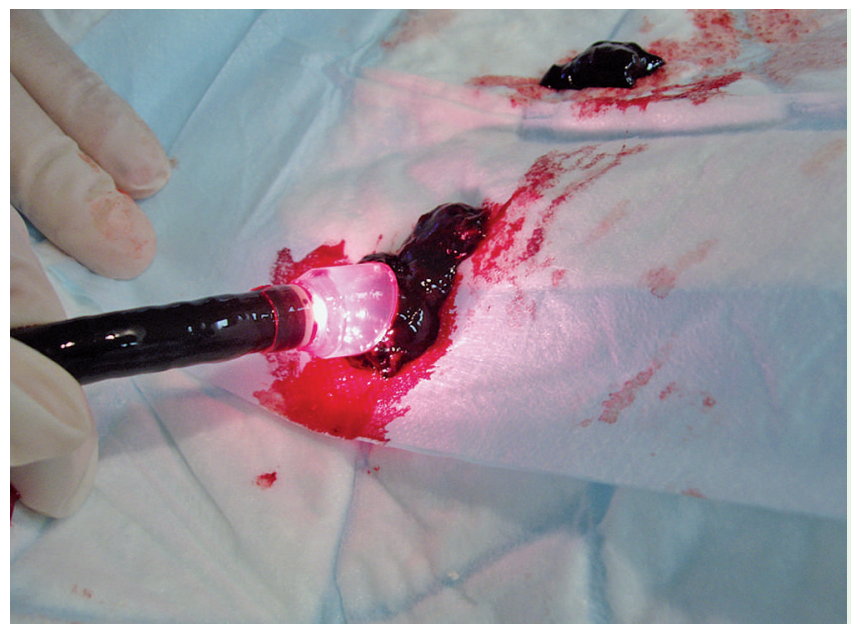

Fig. 1 Distal oblique cap with a rim attached to the endoscope. After aspiration of the clot into the cap, the endoscope is retracted; in this way large clots can be easily removed from the stomach.

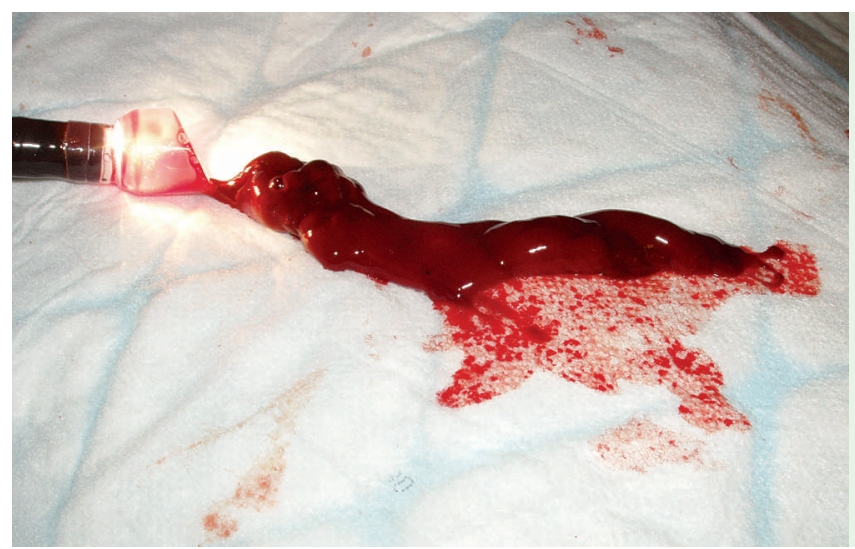

Fig. 2 The large blood clot is easily removed from the cap when aspiration ceases. The flexible oblique shape allows rapid reintubation of the endoscope into the stomach.

Endoscopy_UCTN_Code_TTT_1AO_2AD

\section{T. G. Moreels, M. Lotry, B. Roth,} P. A. Pelckmans

Antwerp University Hospital, Department of Gastroenterology and Hepatology, Wilrijkstraat 10, B-2650 Antwerp, Belgium

\section{References}

1 Gralnek IM, Barkun AN, Bardou M. Management of acute bleeding from a peptic ulcer N Engl J Med 2008; 359: 928 - 937

2 Villanueva C, Colomo A, Aracil C, Guarner C. Current endoscopic therapy of variceal bleeding. Best Pract Res Clin Gastroenterol 2008; 22: 261-278

3 Soehendra N, Binmoeller KF, Seifert H, Schreiber HW. Nonvariceal bleeding. In: Soehendra N, Binmoeller KF, Seifert H, Schreiber HW (eds). Therapeutic endoscopy: color atlas of operative techniques for the gastrointestinal tract. 2nd edn. ((傮tuttgart?): Thieme; 2005: 57 - 71

\section{Bibliography}

DOI $10.1055 / \mathrm{s}-0029-1214694$

Endoscopy 2009; 41: E152

(C) Georg Thieme Verlag KG Stuttgart · New York ISSN 0013-726X

\section{Corresponding author}

\section{T. G. Moreels, MD, PhD}

Antwerp University Hospital

Department of Gastroenterology and Hepatology Wilrijkstraat 10

B-2650 Antwerp

Belgium

Fax: +32-3-8214478

tom.moreels@uza.be 